\title{
STATISTICAL THEORY OF TWO PHASE FLOW \\ AND DETERMINATION OF LOCAL DYNAMIC VAPOR FRACTIONS
}

by

J. W. H. Chi
RECWIVE:

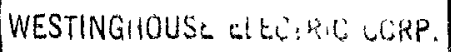

$J A B=1+1963$

ASTRUNUCLEAR LAB LIBRARY

\section{Distribution}

Dr. W. H. Esselman

Dr. W. H. Arnold, Jr.

Mr. H. F. Faught (2)

Dr. E. A. DeZubay

Mr. F. D. Retallick

Mr. J. G. Gallagher

Mr. H. S. McCreary
Dr. A. H. El-Waziri

Mr. C. K. Kim

Mr. K. L. Rieke

Mr. J. W. Sadler

Mr. G. R. Thomas

Mr. A. M. Vetere

Dr. J. D. Holmgren 


\section{DISCLAIMER}

This report was prepared as an account of work sponsored by an agency of the United States Government. Neither the United States Government nor any agency Thereof, nor any of their employees, makes any warranty, express or implied, or assumes any legal liability or responsibility for the accuracy, completeness, or usefulness of any information, apparatus, product, or process disclosed, or represents that its use would not infringe privately owned rights. Reference herein to any specific commercial product, process, or service by trade name, trademark, manufacturer, or otherwise does not necessarily constitute or imply its endorsement, recommendation, or favoring by the United States Government or any agency thereof. The views and opinions of authors expressed herein do not necessarily state or reflect those of the United States Government or any agency thereof. 


\section{DISCLAIMER}

Portions of this document may be illegible in electronic image products. Images are produced from the best available original document. 


\section{SUMMARY}

Based on fluid temperature data obtained from the study of pressurized cool-down to liquid hydrogen, the mechanisms of two-phase flow in the film boiling, transitional and nucleate boiling regions have been discussed in detail.

It has been shown that in the film boiling and transitional regions, thermodynamic equilibrium does not exist between the vapor and the liquid.

Based on the postulated mechanisms, a statistical theory of two-phase flow has been developed. The theory provides a simple method for the determination of dynamic vapor fractions (non-equilibrium mass fraction vapor) from temperature traces. The vapor fractions determined by this method have been verified by those estimated by an independent procedure.

The principles developed suggest the design of a "quality" meter for the determination of non-equilibrium vapor fractions. The meter is a potentially patentable device. 


\section{INTRODUCTION}

During the start-up of a nuclear reactor for space flights, the vapor fraction of the hydrogen propellant at certain locations is critical to the operation of the reactor; consequently, the behavior of transient two-phase flow under given operating conditions must be predicted.

In order to better understand two-phase flow and boiling heat transfer to hydrogen at transient conditions, a test loop was constructed to study the effects of operating variables on cooldown. Due to the fact that no reliable instrument is available or applicable at the present for the measurement of vapor fractions in the system under study, the available experimental data is analyzed in an attempt to develop a method for the determination of vapor fractions. 


\section{EXPERIMENTAL APPARATUS AND PROCEDURE}

Details of the test loop and instrumentation is not within the scope of this memorandum; only a general description is given.

A two foot, 1/4 inch O. D. copper test section, preceded by a 5-3/4 inch length of the same tubing was mounted horizontally in an evacuated chamber. A gas orifice meter, located well downstream from the test section was used to measure the flowrates. The reliability of the orifice meter for the determination of flowrates has been discussed in a previous memorandum ${ }^{1}$. Copper-constantan thermocouples were installed on the outside wall and in the center of the 3/16 inch I. D. tubing to measure the wall and stream temperatures at both the inlet and the exit of the two foot test section. The temperatures were recorded continuously on a Visicorder, made by the Minneapolis-Honeywell Company. The pressure drop across the tube was also measured and recorded continuously.

Immediately prior to the admission of "liquid" hydrogen into the test section, all the piping leading up to it (except the 5-3/4 inch length of straight tubing and a reducer preceding it) was cooled-down to liquid hydrogen temperature by means of a by-pass. Since the test section was well-insulated from the piping leading to it, the fluid admitted came into contact with walls that were initially at ambient temperature.

1. References are appended. 


\section{ANALYSIS OF DATA}

Discussion of Results

A typical schematic inlet stream temperature history covering the unsteady-state period of interest is shown in Figure 1. The temperatures were recorded on a Visicorder at a tape speed of 4 inches per second. Since the test period of interest was generally 20 seconds or more in duration, much of the significance of the temperature fluctuations observed is lost on the time scale used in Figure 1 ; therefore, blow-ups of the temperature traces for typical time increments are reproduced in Figure 2.

Following Figure 1, it is evident that the temperature-time trace is initially very smooth, but fluctuates wildly with time thereafter. A few seconds after the admission of fluid into the test section, saturation temperature appeared fleetingly. With increasing time, the saturation temperature, i. e. , liquid, appeared more frequently and persisted for longer periods. This can be readily seen from the sequence of blow-ups shown in Figure 2. Based on these results, the following mechanisms are postulated for pressurized cool-down in the film boiling region:

Mechanisms of Two-Phase Flow

Initially, due to the large temperature difference between the wall and the saturated liquid, any liquid admitted to the test section is flashed-off to vapor. As the wall temperature or heat transfer decreases, there is insufficient sensible heat within the vapor to boil off all the liquid admitted, resulting in dispersed or "spray" flow. Gradually, the dispersed liquid droplets agglomerate to form slug flow. As seen from Figure 2, the sudden changes in temperatures from vapor to liquid suggest the appearance of al ternate slugs of vapor and liquid. The implied successive modes of heat transfer are: heat transfer to a vapor, film boiling, transitional boiling, and nucleate boiling. A schematic diagram showing the various modes of two-phase flow is shown in Figure 3. The sequence of two-phase flows described above is in general agreement with those observed visually be Bronson, et. al. 2 
In the film boiling regime, the vapor is in equilibrium with the liquid only at the vaporliquid interface. Everywhere else the vapor is superheated. Due to the unsteady nature of heat transfer and the relatively poor conductivity of the vapor, thermodynamic equilibrium can not be attained; therefore, the mass fraction vapor at any instant is not equivalent to the thermodynamic quality. Accordingly, the non-equilibrium mass fraction vapor shall be referred to as the dynamic vapor fraction. 


\section{STATISTICAL THEORY OF TWO-PHASE FLOW}

Based on the experimental data, it has been concluded that in the film boiling regime, the vapor-liquid phases are not in equilibrium. In fact, substantial temperature differences were observed. Under the conditions of the experiments, the two-phase flow through the 3/16 inch I.D. test section is highly turbulent; therefore, it can be assumed that the two-phase fluid exists as a homogeneous mixture with the vapor at an average temperature $T_{v}$ and the liquid at its saturation temperature, $\mathrm{T}_{\text {sat }}$. This implies that the liquid droplets are in random motion.

Consider the thermocouple bead as the control volume. In mist flow, if the droplets of liquid are equal to or smaller than the control volume, then the appearances of saturation temperatures are instantaneous. If the liquid droplets or slugs are large relative to the control volume, then saturation temperatures will appear for a finite period.

Frequency and Probability

Let $\Delta t_{1}$ be an arbitrary increment of time defining a unit appearance of liquid, and $t_{\text {I }}$ the cumulative liquid life, then the total number of times liquid temperature have appeared at time $t$ is given by

$$
n=\frac{t_{1}}{\Delta t_{1}}
$$

The frequency of observing liquid temperature $\Gamma_{I^{\prime}}$, is merely the derivative of $n$ with time

$$
\Gamma_{1}=\frac{d n}{d t}=\frac{1}{\Delta t_{1}}\left(\frac{d t_{1}}{d t}\right)
$$

It follows that the probability of observing liquid, $P_{I}$ is $\frac{d t_{1}}{d t}$, or 


$$
P_{I}=\Delta t_{1} \frac{d n}{d t}=\frac{d t_{I}}{d t}
$$

The probability of vapor appearing,

$$
P_{v}=1-P_{1}=1-\frac{d t_{1}}{d t}
$$

The cumulative liquid life was determined from the Visicorder tape and it can be plotted versus the total time. A typical curve of $t_{1}$ vs $t$ is shown in Figure 4. It was evident from the large amount of existing data that in the absence of sudden external disturbances, such as pressure surges and heat leaks, the liquid life is a continuous and single-valued function of time.

The probabilities of observing liquids for two typical runs at different flowrates are presented in Figure 5 as a function of the total time. By definition, the total time is the sum of the cumulative liquid and vapor lives:

$$
t=t_{1}+t_{v}
$$

It is evident that at very long times when the line has cooled-down to the liquid temperature, $t_{v}$ becomes a constant and the probability of observing liquid approaches 1. At the start of the run, if the liquid temperature does not appear at all, then $t=t_{v}$ and the probability of observing vapor is 1, i.e., the liquid is completely vaporized. 


\section{DYNAMIC VAPOR FRACTIONS}

Let it be assumed that the temperatures measured in the middle of the stream are representative of those in the entire cross section. Assuming further that in mist flow, the vapor and liquid are in random motion and that in slug flow, vapor film thicknesses are negligible, then if a large number of temperature measurements are made per second, i. e., relatively high Visicorder tape speed, the volume fraction liquid is directly proportional to the frequency or probability of observing the liquid:

$$
v_{1}=\alpha \Gamma_{1}=\frac{\alpha}{\Delta T_{1}} P_{1}
$$

Similarly, the volume fraction vapor is proportional to the frequency of observing vapor temperatures:

$$
v_{v}=\alpha \Gamma_{v}=\frac{\alpha}{\Delta t_{1}} p_{v}=\frac{\alpha}{\Delta t_{1}} \quad\left(1-p_{1}\right)
$$

where $\alpha$ is a proportionality constant. By definition, the local instantaneous mass fraction vapor can be calculated from the equation

$$
\bar{y}=\frac{\bar{\rho}_{v} v_{v}}{\rho_{v} v_{v}+\rho_{I} v_{I}}
$$

In terms of probabilities, Equation ( 8 ) becomes

$$
\bar{y}=\frac{\bar{o}_{v}\left(1-P_{1}\right)}{P_{v}\left(1-P_{1}\right)+P_{1} P_{1}}
$$


The vapor density, $\bar{D}_{v}$ can be determined from the average vapor temperature.

The instantaneous local vapor fractions for the inlet to the test section were calculated by this method. The results of two typical runs at different flowrates are shown in Figure 6 .

Dynamic Vapor Fractions at the Exit to the Test Section

Due to the fact that heat was transferred to the fluid along the length of the test section, the liquid was vaporized continuously down the test section, and the corresponding slug flow phenomenon at the exit to the test section was not observed until a much later period. By this time, the line had cooled down considerably so that the temperature fluctuations (between vapor and liquid) were less pronounced and liquid life could not be determined readily. However, based on the vapor fractions calculated for the inlet to the test section, those at the outlet can be computed from energy balances as discussed below.

In view of the relatively high conductivity of copper and the thin wall of the tubing, the average instantaneous heat flux from the wall to the fluid can be defined as

$$
\bar{Q}=\frac{\pi}{4} \rho\left(D_{0}^{2}-D_{i}^{2}\right) L \frac{\overline{C_{p} d T_{w}}}{d t}
$$

where $L$ is the length of the test section, $D_{0}$ and $D_{i}$ are outside and inside tube diameters. The slope d T

$\frac{d}{d t}$ for the inlet and exit of the test section can be determined by either graphical or numerical differentiation of the local wall temperature histories. A linear enthalpy change with time can be assumed, whence 


$$
C_{p} \frac{d T_{w}}{d t}=\frac{\left(C_{p} \frac{d T_{w}}{d t}\right)_{1}+\left(C_{p} \frac{d T_{w}}{d t}\right)_{2}}{2}
$$

The subscripts 1 and 2 refer to the inlet and outlet of the test section, respectively. For a good approximation, it can be assumed that all the heat transferred to the two-phase fluid is used to vaporize the liquid. The vapor fraction at the exit can then be calculated from the average heat flux by the following relationship:

$$
y_{2}=y_{1}+\frac{\bar{Q}}{\lambda W}
$$

where $\lambda$ is the latent heat of vaporization and $W$ is the instantaneous mass flowrate.

\section{Alternate Method for Estimating Average Vapor Fractions}

It was noted from the data that for some runs, a time lag clearly existed between the inlet and exit temperature traces. The distance between the two locations divided by the time $\operatorname{lag}, T$ gives the instantaneous average two-phase fluid velocity in the test section, $V_{T P}$. By definition, the instantaneous average two-phase fluid density over the test section is given by

$$
\rho_{\mathrm{TP}}=\frac{\mathrm{W}_{\mathrm{TP}}}{\mathrm{V}_{\mathrm{TP}} \mathrm{S}}
$$

where $W_{T P}$ is the mass flowrate, and $S$ is the inside tube cross-sectional area. 
It follows that the average mass fraction vapor over the tube, $\bar{y}$, can be computed from the equation

$$
\bar{y}=\frac{\bar{\rho}_{v} v_{v}}{\rho_{T P}}
$$

where $v_{v}$ is the volume fraction of vapor. Based on a unit volume of two-phase fluid, the average two-phase fluid density is related to the vapor and liquid densities by the equation

$$
\bar{\rho}_{\mathrm{TP}}=\bar{\rho}_{\mathrm{v}} v_{\mathrm{v}}+\rho_{1}\left(1-v_{\mathrm{v}}\right)
$$

or

$$
v_{v}=\frac{\rho_{1}-\bar{\rho}_{\mathrm{TP}}}{\rho_{1}-\bar{\rho}_{\mathrm{v}}}
$$

Substituting into (14), the equation becomes

$$
\bar{y}=\frac{\bar{\rho}_{\mathrm{V}}\left(\rho_{1}-\bar{\rho}_{\mathrm{TP}}\right)}{\rho_{\mathrm{TP}}\left(\rho_{1}-\bar{\rho}_{\mathrm{V}}\right)}
$$

If the average instantaneous fluid velocity is known, then the average fluid density can be determined from Equation (13), and the average vapor fraction can be computed from Equation (16). 
Based on this method, the average vapor fractions over the entire test section were estimated. The results for two runs are compared with the inlet and exit instantaneous vapor fractions calculated from the statistical method in Figures 7 and 8 for two different flowrates. Arithmetic average vapor fractions based on the local inlet and outlet values were calculated and plotted versus those estimated from fluid velocities in Figure 9. As seen from this figure, the vapor fractions determined by the two methods are in good agreement. The values estimated from velocities were on the average $10 \%$ lower than those computed from statistical theory. 


\section{DISCUSSIONS}

Effect of Thermocouple Response Time on Vapor Fractions

When a sudden change in temperature is impressed on a thermocouple, a finite time (response time) elapses before the thermocouple will indicate the impressed temperature. The response time can be calculated from the equation

$$
{ }_{r}=-\frac{\rho_{V}}{A} \int_{T_{0}}^{T_{f}} \frac{C}{h} \frac{d T}{\left(T-T_{f}\right)}
$$

$$
\text { where } \quad \begin{aligned}
t_{r} & =\text { the response time } \\
\rho & =\text { density of the thermocouple (bead) } \\
V & =\text { effective volume of the thermocouple (bead) } \\
A & =\text { effective surface over the thermocouple (bead) } \\
C & =\text { heat capacity of the thermocouple (bead) } \\
T & =\text { temperature of the thermocouple (bead) } \\
h & =\text { local instantaneous heat transfer coefficient } \\
T_{f} & =\text { fluid temperature }
\end{aligned}
$$

The response time is a function of the fluid velocity as well as $\Delta T$. Experimentally, it was found that the response time decreases with decreasing $\Delta T$.

It is obvious that if the liquid life is less than the response time, saturation temperature will not be attained, but sharp temperature fluctuations would be observed on the Visicorder. The short liquid lives and the large $\Delta T$ 's at the beginning of cool-down indicate that any significant errors in the estimated vapor fractions would occur at this period. 
Qualitatively, a correction of cumulative liquid life by taking into account thermocouple response time would give lower vapor fractions calculated from statistical theory. From the comparison of vapor fractions estimated by the two different methods, it appears that this would provide better agreements.

Vapor Fractions in the Transitional and Nucleate Boiling Regimes

The determination of vapor fractions can be extended to the transitional and nucleate boiling regimes if the vapor is not in equilibrium with the liquid, i. e., observable vapor-liquid temperature differences. In this investigation, the data showed that the vapor fractions decreased to less than $2 \%$ before nucleate boiling occurred. Since this is probably within the accuracy of the method, vapor fraction determinations were not extended beyond the film boiling region.

The Dynamic Nature of Two-Phase Flow During Cool-Down

The most important conclusion resulting from this work is that thermodynamic equilibrium between the vapor and liquid phases does not exist in the film boiling and transitional regimes during cool-down.

Previous investigators 3,4 on two-phase flows and boiling heat transfer to hydrogen in steady-state systems did not measure stream temperatures but assumed that the vapor and liquid are in equilibrium. On this basis, the vapor fractions or qualities were determined with the aid of thermodynamic properties and charts. It becomes obvious that the application of the same assumption to the unsteady-state system studied here can introduce serious errors in the vapor fractions determined.

"Quality" Meter

It is proposed that a "quality" meter can be designed on the basis of the principles discussed here. It is apparent that the criteria for the design of such a meter is turbulent flow 
and substantial differences in vapor-liquid temperatures. Detailed proposals on such a meter have been ${ }^{5}$ and shall be discussed elsewhere.

In view of the fact that no method exists at the present for the determination of dynamic vapor fractions, the "quality" meter proposed for the measurement of local dynamic vapor fractions appears to be a potentially patentable device; however, further research is necessary in order to fully understand the conditions under which the statistical theory can be applied.

Actual experimental measurements on vapor fractions are necessary in order to check the reliability and the accuracy of the statistical method. 


\section{NOMENCLATURE}

\begin{tabular}{|c|c|}
\hline $\mathrm{Cp}$ & Heat capacity of the copper tube. \\
\hline D & Diameter. \\
\hline $\mathbf{L}$ & Length of the test section. \\
\hline$n$ & Number of times liquid temperature have been observed. \\
\hline $\mathbf{P}$ & Probability \\
\hline $\bar{Q}$ & $\begin{array}{l}\text { Average heat flux from the wall to the fluid in the test } \\
\text { section. }\end{array}$ \\
\hline S & Inside tube cross-sectional area. \\
\hline$t$ & Total time. \\
\hline$t_{1}$ & Cumulative liquid life. \\
\hline$t_{v}$ & Cumulative vapor life. \\
\hline$\Delta t_{1}$ & A constant. \\
\hline $\mathrm{T}$ & Temperature. \\
\hline $\mathbf{v}$ & Volume fraction. \\
\hline V & Average fluid velocity. \\
\hline W & Mass flowrate. \\
\hline y & Mass fraction vapor. \\
\hline$\alpha$ & Proportionality constant. \\
\hline$\Gamma$ & Frequency. \\
\hline$\lambda$ & Latent heat of vaporization. \\
\hline$\rho$ & Density. \\
\hline $\mathcal{T}$ & $\begin{array}{l}\text { Lag time between temperature traces at the inlet and outlet } \\
\text { of the test section. }\end{array}$ \\
\hline
\end{tabular}


NOMENCLATURE (Con't.)

$\begin{array}{ll}\text { Subscripts: } & \\ \text { i } & \text { Inside } \\ \text { I } & \text { Saturated liquid } \\ 0 & \text { Outside } \\ \text { TP } & \text { Two-phase } \\ \text { v } & \text { Vapor } \\ \text { w } & \text { Wall } \\ \text { I } & \text { Inlet } \\ 2 & \text { Outlet }\end{array}$




\section{REFERENCES}

1. Chi, J. W. H., "Fluid Flow and Transient Heat Transfer of Gaseous Hydrogen at Low Temperatures", WANL-TMI-344

2. Bronson, J. C., et. al., "Problems in Cool-Down of Cryogenic Systems", Advances in Cryogenic Engineering, Vol. 7, Plenum Press, New York, 1962, p. 201.

3. Wright, C. C., and Walters, H. H., "Single Tube Heat Transfer Tests, Gaseous and Liquid Hydrogen", WADC Technical Report 59-423, 1959.

4. Hendricks, R. C., et. al., "Experimental Heat Transfer and Pressure Drop of Liquid Hydrogen Flowing Through A Heated Tube", NASA-TN D-765, 1961.

5. Chi, J. W. H. to DeZubay, E. A., "A Meter for Measuring Dynamic Mass Fraction Vapor in Two-Phase Flow", FF-143, November 6, 1962. 




FIGURE 1. TYPICAL SCHEMATIC INLET FLUID TEMPERATURE HISTORY

ำ 


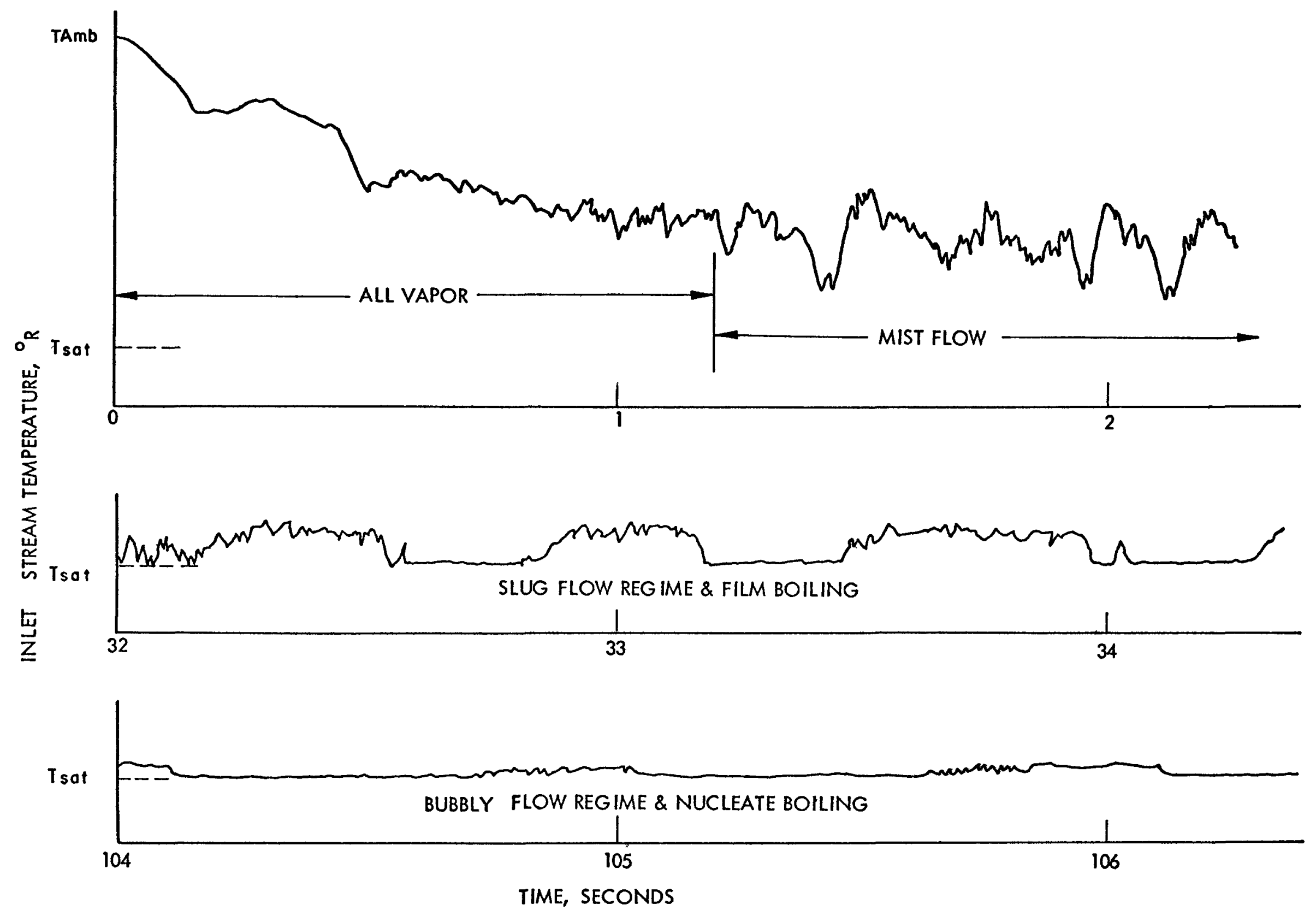

FIGURE 2 VISICORDER TEMPERATURE TRACES SHOWING VARIOUS FLOW REG IMES DURING COOL-DOWN 




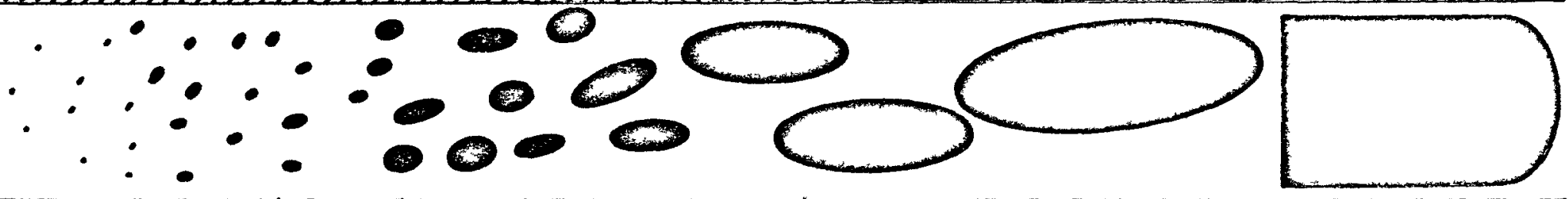

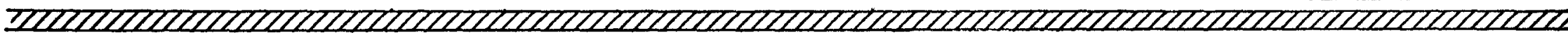



ZIITH
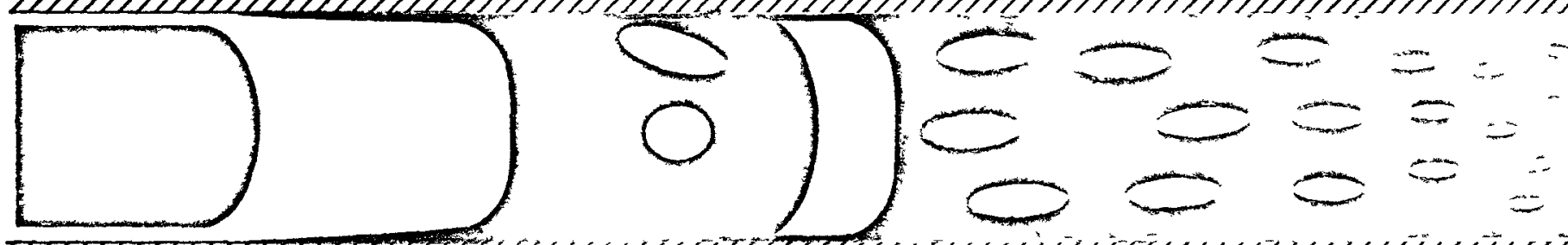

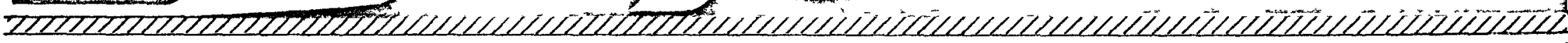

SLUG FLOW

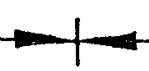

BUBBLY FLOW

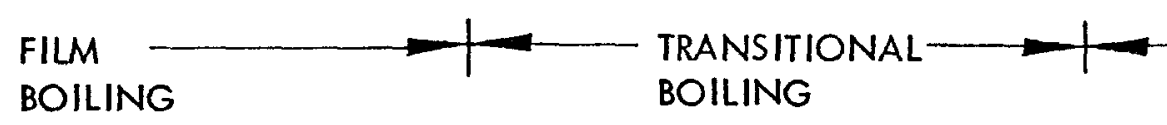

\section{NUCLEATE} BOILING

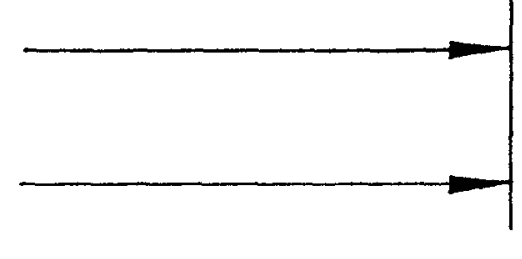

FIGURE 3. SCHEMATIC DIAGRAM ON THE VARIOUS TWO PHASE FLOW REG IMES AND MODES OF HEAT TRANSFER DURING COOL-DOWN 


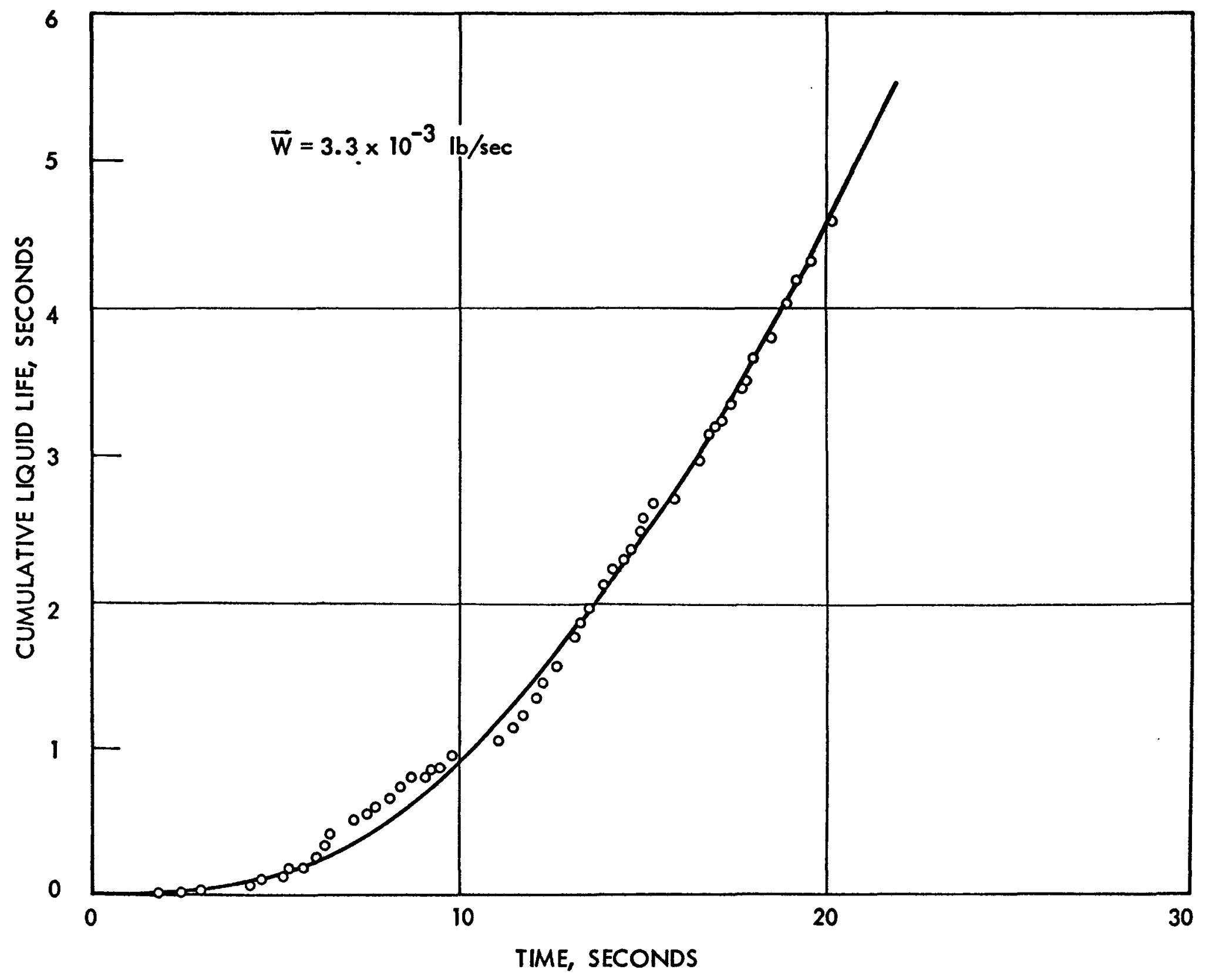

18)

FIGURE 4. TYPICAL LIQUID LIFE HISTORY 


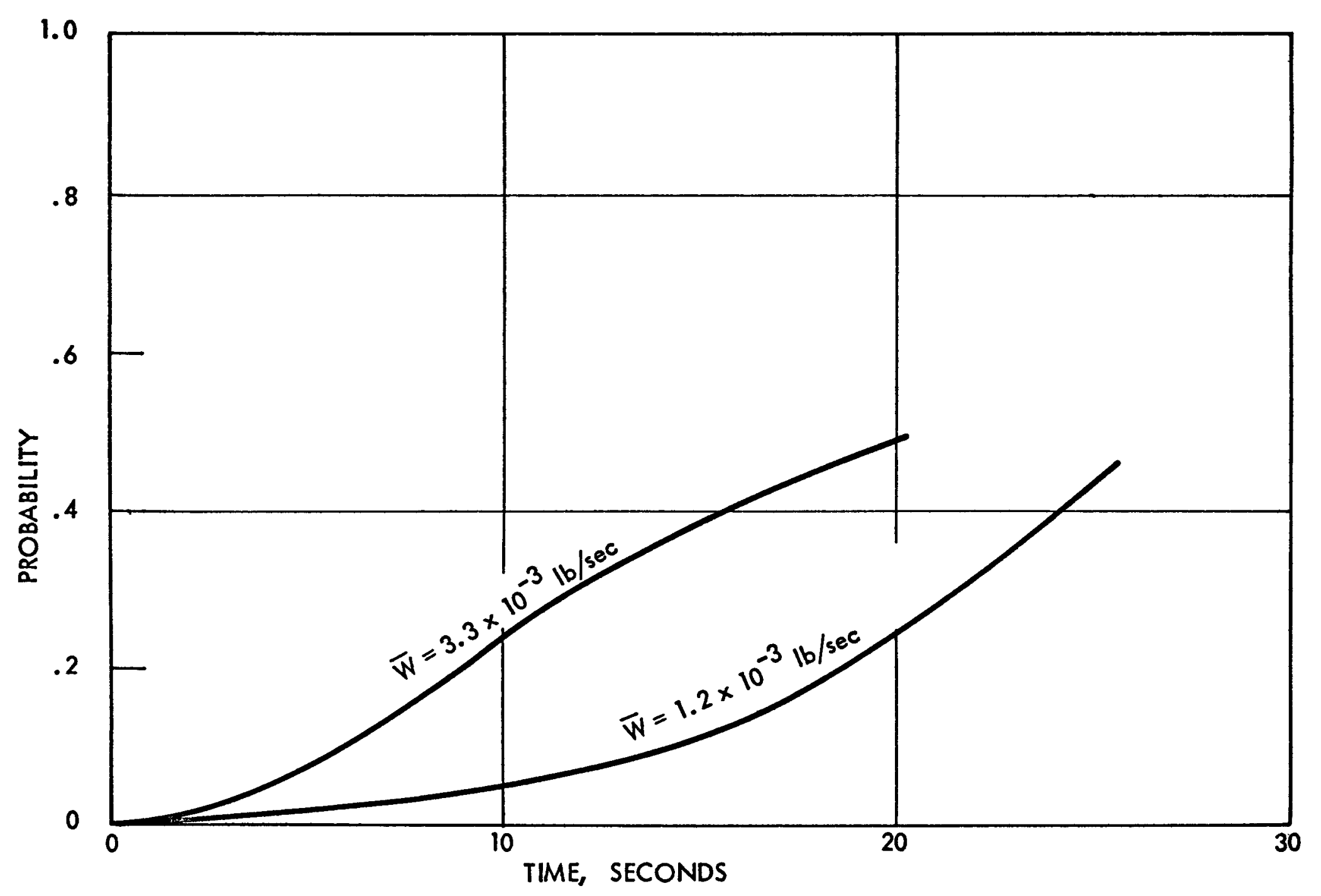

FIGURE 5. PROBABILITY OF MEASURING LIQUID TEMPERATURES 


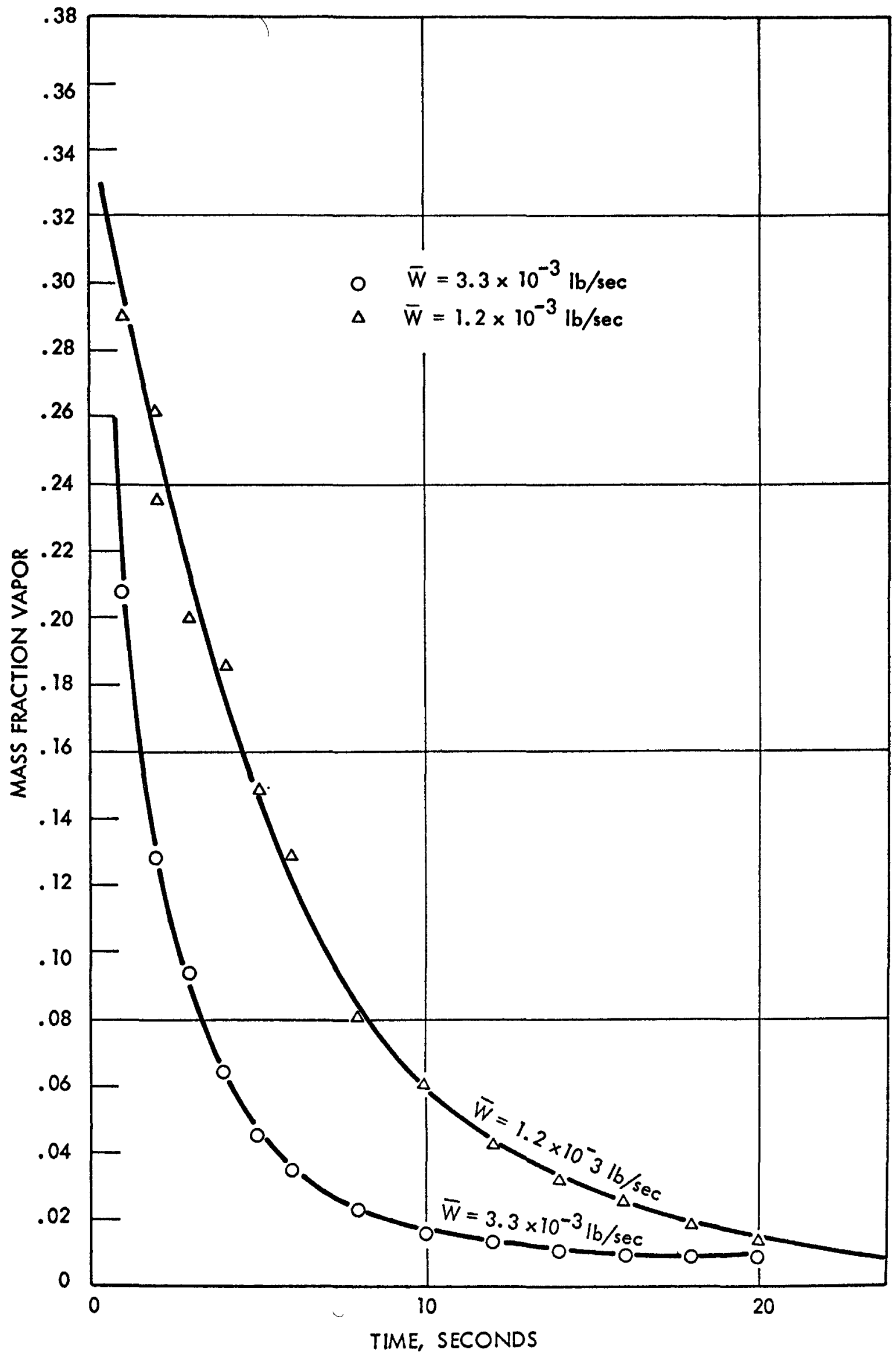

FIGURE 6. TYPICAL INLET VAPOR FRACTION HISTORIES 


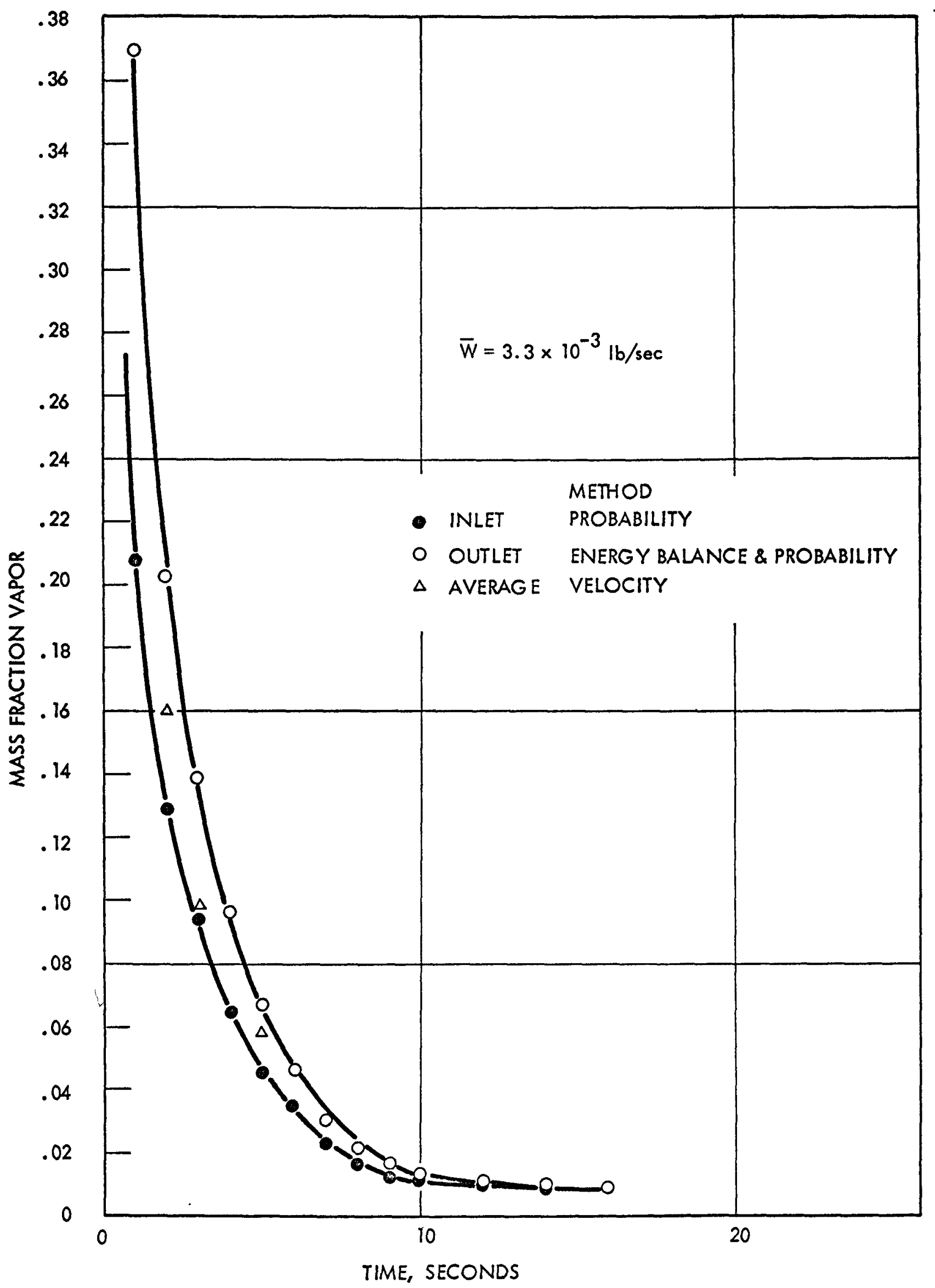

FIGURE 7. COMPARISON OF CALCULATED VAPOR FRACTIONS 


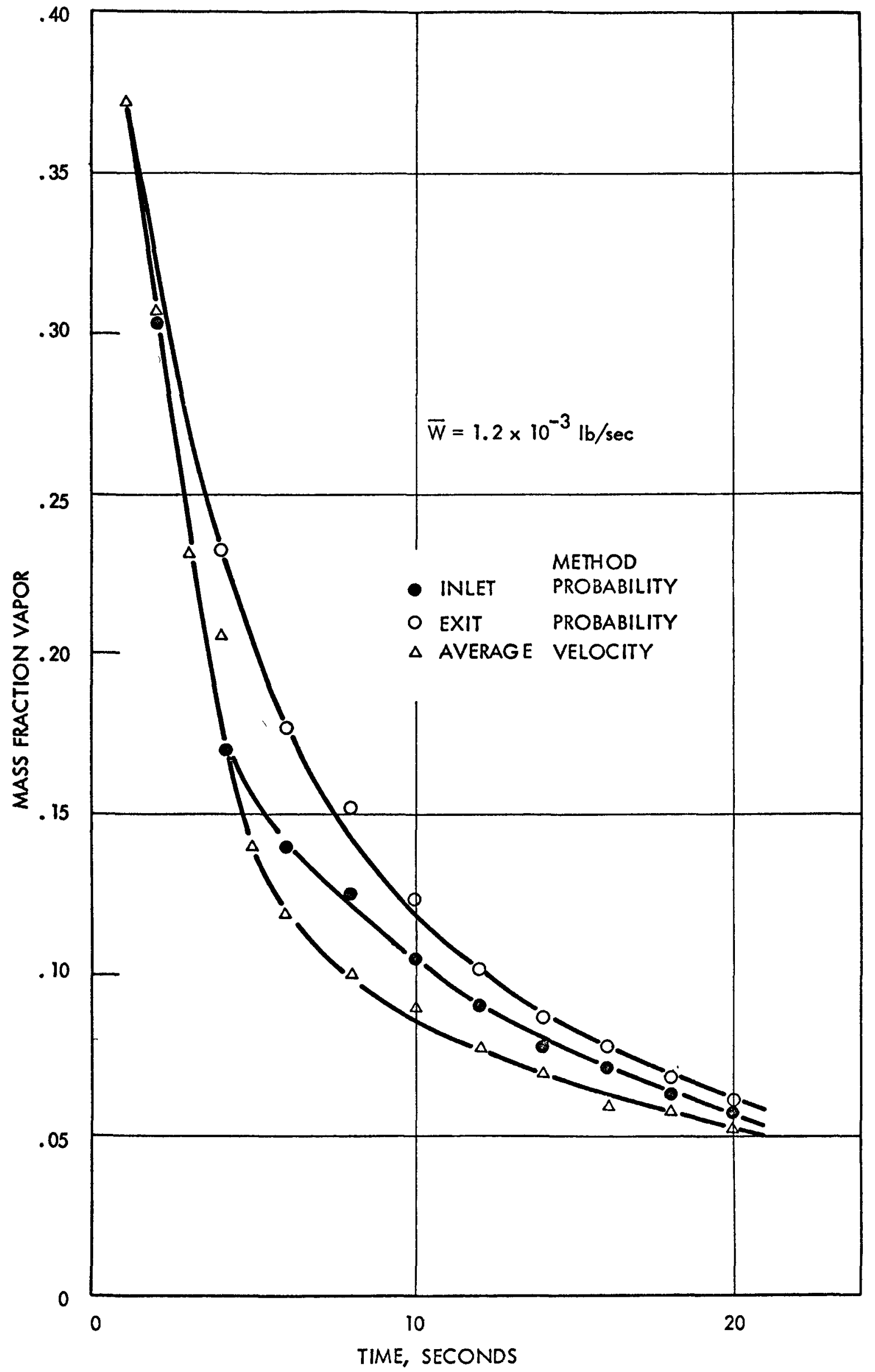

FIGURE 8. COMPARISON OF CALCULATED VAPOR FRACTIONS 


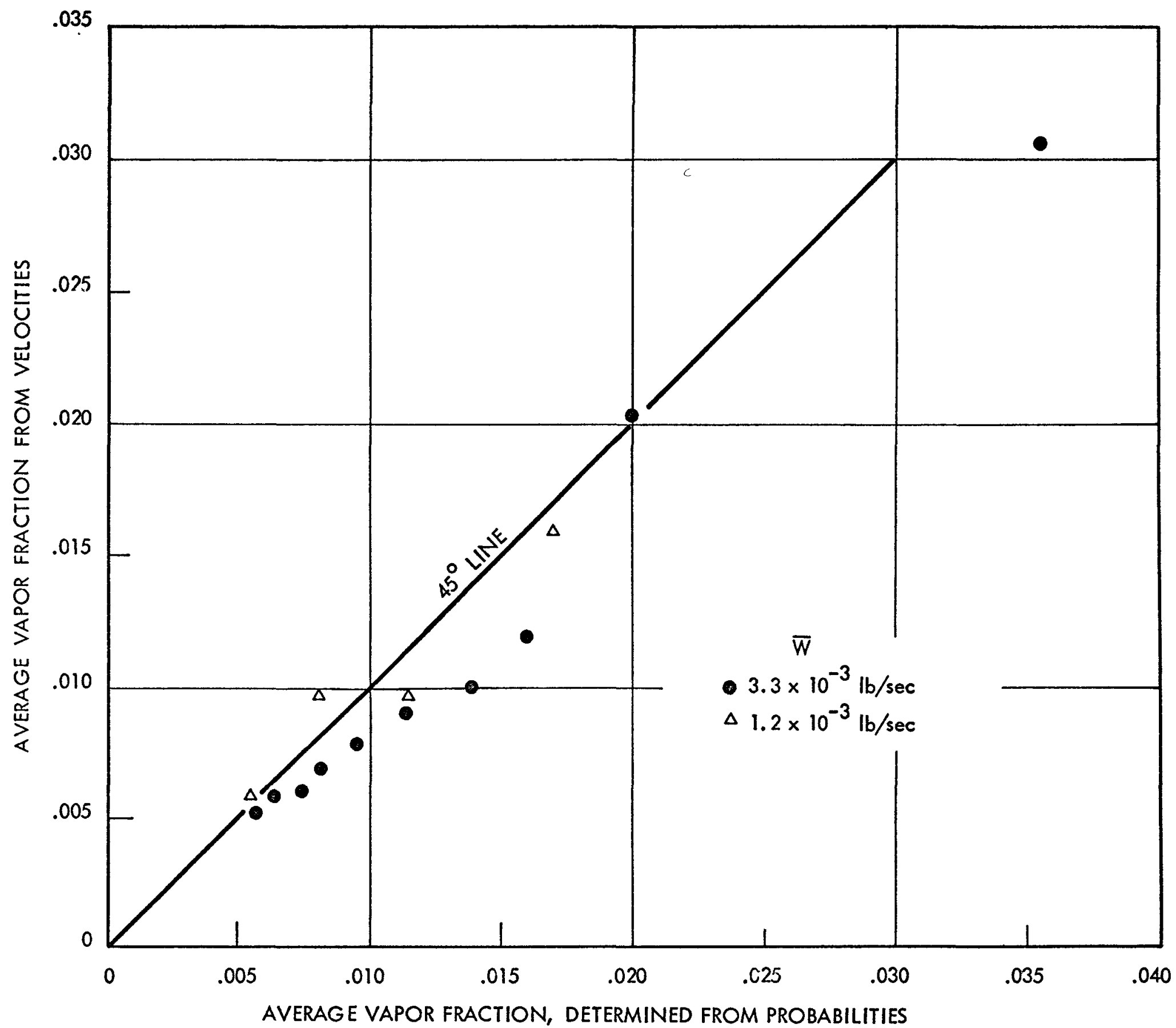

18 